\title{
PENGEMBANGAN SISTEM INFORMASI PENERIMAAN MAHASISWA BARU DENGAN SMS GATEWAY (Studi Kasus Universitas Islam Kalimantan)
}

\author{
Muhammad Edya Rosadi ${ }^{1)}$, Indu Indah Purnomo²), Muhammad Iqbal Firdaus ${ }^{3)}$ \\ ${ }^{1}$ Fakultas Teknologi Informasi, Universitas Islam Kalimantan \\ Surel: edya@fti.uniska-bjm.ac.id \\ ${ }^{2}$ Fakultas Teknologi Informasi, Universitas Islam Kalimantan \\ Surel: indumbc@gmail.com \\ ${ }^{3}$ Fakultas Teknologi Informasi, Universitas Islam Kalimantan \\ Surel: m.iqbal1412@gmail.com
}

\begin{abstract}
ABSTRAK
Popularitas sebuah universitas dapat dilihat dari banyaknya calon mahasiswa baru yang berminat untuk masuk pada universitas tersebut. Universitas Islam Kalimantan adalah salah satu contoh universitas dengan peminat paling tinggi di Kalimantan Selatan, tidak kurang 4.000 calon mahasiswa mendaftar setiap tahun, terutama dalam empat tahun terakhir. Dengan banyaknya calon mahasiswa tersebut haruslah dikembangkan sebuah sistem yang yang mana selalu mempermudah dalam penyampaian informasi terkait dengan alur pendaftaran, proses seleksi, biaya perkuliahan dan sebagainya, sistem ini harus dibuat otomatis agar dapat dengan cepat dan tanpa bosan menjawab pertanyaan dari calon mahasiswa. Berkembangnya teknologi sekarang ini menawarkan sebuah fitur bernama SMS Gateway, dengan fitur ini pengguna dapat mengirimkan pesan singkat ke sistem sesuai dengan kata kunci tertentu dan akan dibalas otomatis oleh sistem. Selain itu sistem juga dapat mengirimkan pesan singkat secara masal agar informasi cepat tersampaikan kepada pengguna. Dalam penelitian ini fitur SMS Gateway berhasil diintegrasikan dengan sistem penerimaan mahasiswa baru yang telah ada sebelumnya pada Universitas Islam Kalimantan, penggunaan metode Waterfall membuat perancangan sistem menjadi lebih mudah.
\end{abstract}

Keywords: penerimaan mahasiswa baru, sms gateway, sistem informasi, metode waterfall

\section{PENDAHULUAN}

Universitas Islam Kalimantan Muhammad Arsyad Al Banjari adalah merupakan salah satu perguruan tinggi swasta yang berada di Kalimantan Selatan. Didirikan tahun 1981, kini universitas ini menjadi universitas dengan jumlah mahasiswa terbesar di Kalimantan. Menurut pangkalan data perguruan tinggi pada tahun akademik 2016/2017 ada sebanyak 12.499 mahasiswa yang menuntut ilmu terbagi pada 9 fakultas dan 2 program pascasarjana yang ada pada universitas ini.

Penyelenggaraan penerimaan mahasiswa baru tentu sangat berperan penting dalam menentukan banyaknya jumlah mahasiswa yang masuk. Dalam tiga tahun terakhir Universitas Islam Kalimantan berhasil menarik tidak kurang 4.000 lebih calon mahasiswa setiap tahunnya. Sistem informasi penerimaan mahasiswa baru pun telah berganti, dari yang berbasis desktop menjadi berbasis web. Ini tidak lain agar proses pendaftaran mahasiswa baru menjadi lebih mudah.

Berkembangnya teknologi dan informasi memang telah memudahkan proses dan pekerjaan manusia, data calon mahasiswa menjadi lebih cepat dan tepat diperoleh karena dari awal alur pendaftaran telah dilakukan dengan sistem informasi. Namun sistem informasi penerimaan mahasiswa baru sekarang dapat dikembangkan agar menjadi lebih baik lagi. Salah satu kekurangan adalah tidak sampainya informasi lanjutan kepada calon mahasiswa setelah melakukan pendaftaran, misalnya informasi jadwal tes tertulis, informasi waktu pendaftaran ulang setelah mahasiswa dinyatakan lulus dan juga informasi besarnya biaya perkuliahan.

Banyaknya calon mahasiswa setiap tahun perlu adanya fitur penyampaian informasi 
yang dapat dilakukan secara masal kepada seluruh calon mahasiswa atau juga dapat menjawab otomatis pertanyaan mahasiswa mengenai alur dan proses pendaftaran. Fitur yang dapat ditawarkan dan lagi berkembang sekarang adalah SMS Gateway, di mana dengan fitur ini sistem dapat langsung mengirimkan informasi kepada semua calon mahasiswa berdasarkan data nomor telepon yang telah diberikan oleh calon mahasiswa saat pendaftaran. Fitur ini juga dapat menjawab otomatis SMS calon mahasiswa berdasarkan kata kunci (keyword) yang telah diatur pada sistem.

Dengan penambahan fitur ini dapat membantu sistem informasi penerimaan mahasiswa baru yang telah ada menjadi lebih berkembang. Dan diharapkan mempermudah penyampaian informasi secara masal dan otomatis, sehingga terjadi peningkatan pelayanan terhadap calon mahasiswa.

\section{LANDASAN TEORI}

1) Penerimaan Mahasiswa Baru

Penerimaan mahasiswa baru adalah salah satu proses akademik yang terdapat pada sebuah universitas. Alur penerimaan mahasiswa baru biasanya telah diatur masingmasing universitas, dengan alur umum antara lain:

1. Proses pendaftaran

2. Seleksi administrasi

3. Seleksi tertulis, psikotes dan anti narkotika

4. Daftar ulang bagi mahasiswa yang dinyatakan lulus.

Pelaksanaannya adalah satu kali setiap tahun untuk perkuliahan mahasiswa baru pada semester ganjil.

\section{2) SMS Gateway}

SMS merupakan singkatan dari Short Message Service yaitu komponen layanan komunikasi teks dari sistem komunikasi mobile yang menggunakan standar protokol komunikasi yang memungkinkan pertukaran pesan antara perangkat telepon genggam (Saxena, 2011). Dalam sistem SMS, mekanisme utama yang dilakukan dalam suatu sistem adalah melakukan pengiriman pesan dari satu terminal pelanggan ke terminal yang lain. Hal ini dapat dilakukan berkat adanya sebuah entitas dalam sistem SMS yang bernama Short Message Service Center (SMSC), atau disingkat Message Center. Pada saat pesan SMS dikirim dari telepon genggam pesan tersebut tidak langsung dikirim ke telepon genggam tujuan, akan tetapi dikirim terlebih dahulu ke SMSC, baru kemudian pesan tersebut dikirimkan ke telepon genggam tujuan.

Layanan SMS Gateway menyediakan layanan dari phone to computer atau dari computer to phone. Layanan SMS Gateway memungkinkan untuk melakukan registrasi melalui perangkat mobile ke suatu website/situs (Karch, 2010). SMS Gateway merupakan teknologi SMS yang dapat diintegrasikan dengan berbagai aplikasi sesuai dengan kebutuhan. Fitur-fitur yang ada seperti $S M S$ broadcast, SMS autoreply, SMS autosend yang banyak digunakan untuk menunjang berbagai kegiatan. Terdapat banyak aplikasi yang dapat digunakan untuk membangun SMS Gateway antara lain Gammu, NowSMS dan PlaySMS.

\section{METODE PENELITIAN}

1) Tahapan Penelitian

Dalam metode penelitian ini terdapat beberapa tahapan yang dilakukan, tahapan tersebut antara lain:

a. Identifikasi masalah

Pada metode ini akan diidentifikasi keseluruhan masalah yang akan dipecahkan menggunakan aplikasi yang akan dibuat. Dari masalah inti, kemudian akan dipecahkan bagian per bagian sehingga dapat dibuat logika pemecahan masalahnya.

b. Analisis Kebutuhan Sistem

Metode ini bertujuan untuk menganalisis apa saja yang dibutuhkan dalam pengembangan aplikasi sistem informasi kinerja penelitian, termasuk kebutuhan hardware dan software-nya.

c. Perancangan Sistem

Metode perancangan sistem informasi ini menggunakan model pengembangan Waterfall.

d. Implementasi sistem menggunakan PHP, MySQL dan Gammu

Setelah semua perancangan sistem selesai, maka akan dilakukan implementasi sistem dengan menggunakan bahasa pemrograman PHP, basis data MySQL dan Gammu sebagai komponen SMS Gateway.

2) Lokasi Penelitian

Penelitian dilakukan pada Universitas Islam Kalimantan Muhammad Arsyad Al- 
Banjari bagian Penerimaan Mahasiswa Baru (PMB)

\section{ANALISA SISTEM}

1) Sistem yang Diusulkan

Sistem Informasi Penerimaan Mahasiswa Baru di Universitas Islam Kalimantan yang ada pada saat penelitian ini dilakukan sudah menggunakan laman daring, dapat diakses melalui tautan https://pmb.uniska-bjm.ac.id/; Dari pengamatan penggunaan sistem terdahulu telah mudah dalam hal pemakaian, ketersediaan data yang lengkap khususnya data diri dan nomor telepon calon mahasiswa dapat langsung digunakan pada fitur SMS Gateway yang diusulkan pada penelitian ini. Sistem yang akan dibuat nantinya akan terpisah dengan sistem terdahulu, namun penggunaannya akan terintegrasi dengan pemakaian basis data yang sama. Selain itu ada penambahan perangkat keras berupa modem (penelitian ini menggunakan modem jenis Wavecom Fastrack M1306B) dan SIM card untuk pengiriman $S M S$.

2) Rancangan Antar Muka Sistem

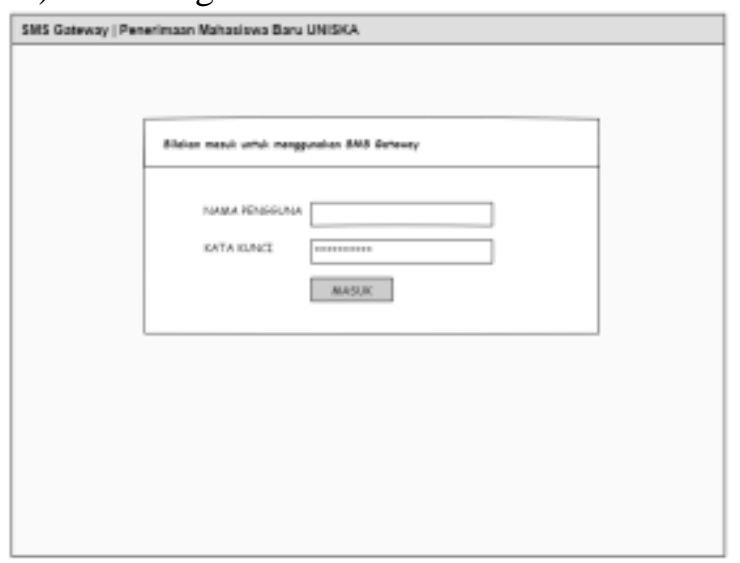

Gambar 1. Rancangan Laman Masuk Sistem

Laman ini digunakan sebagai pengaman untuk masuk ke dalam sistem, hanya pengguna yang memiliki akun dan kata kunci yang dapat masuk sistem, sebaliknya pengguna yang tidak memiliki akses tidak dapat masuk dan menggunakan sistem.

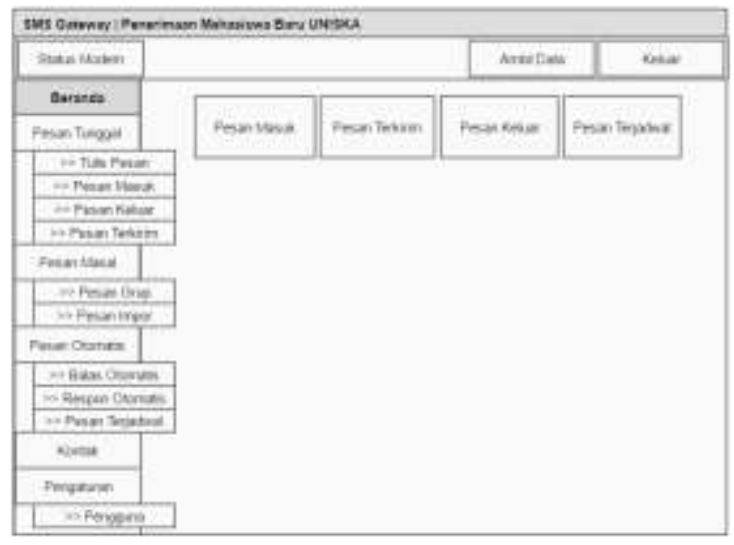

Gambar 2. Rancangan Laman Beranda

Laman beranda adalah laman pertama yang tampil ketika pengguna berhasil masuk ke dalam sistem.

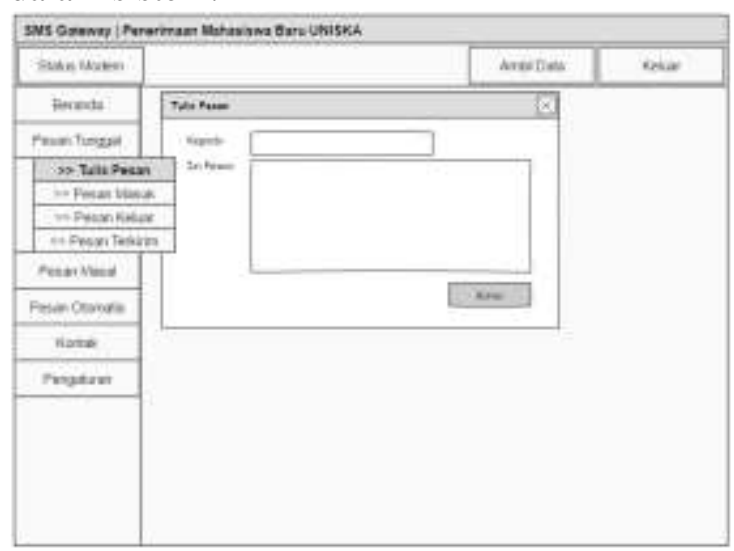

Gambar 3. Rancangan Laman Tulis Pesan

Laman tulis pesan merupakan laman untuk mengirim pesan ke salah satu kontak yang telah tersimpan (pesan tunggal).

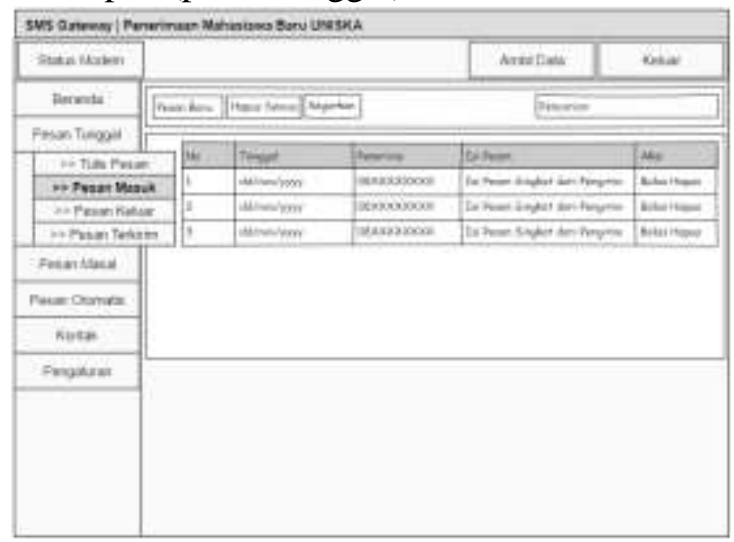

Gambar 4. Rancangan Laman Pesan Masuk

Pada laman ini terdapat daftar pesan yang masuk ke dalam modem dan tersimpan di dalam basis data. 


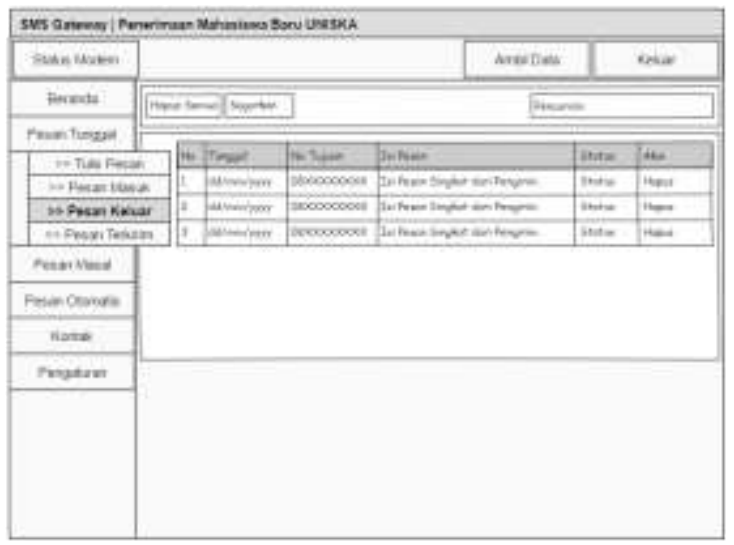

Gambar 5. Rancangan Laman Pesan Keluar

Laman pesan keluar berisi pesan yang telah dikirimkan namun belum sampai ke nomor tujuan, ditandai dengan status menunggu terkirim.

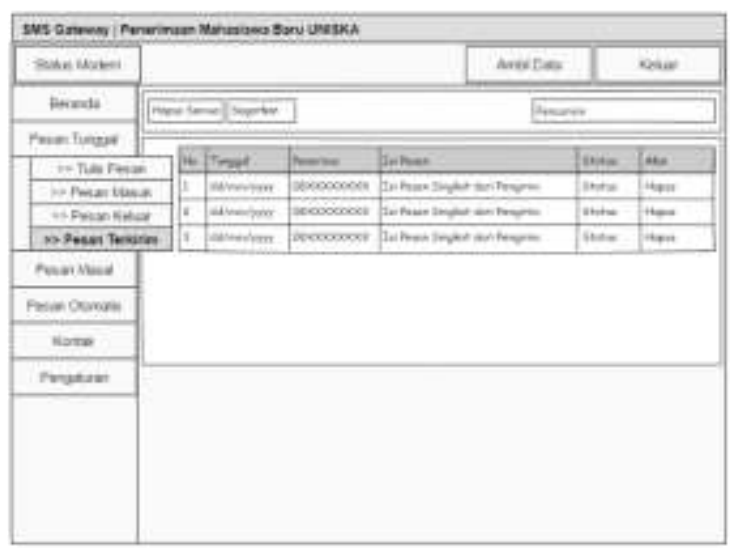

Gambar 6. Rancangan Laman Pesan Terkirim

Laman pesan terkirim ini menampung semua data pesan yang telah terkirim, merupakan pindahan data dari pesan keluar.

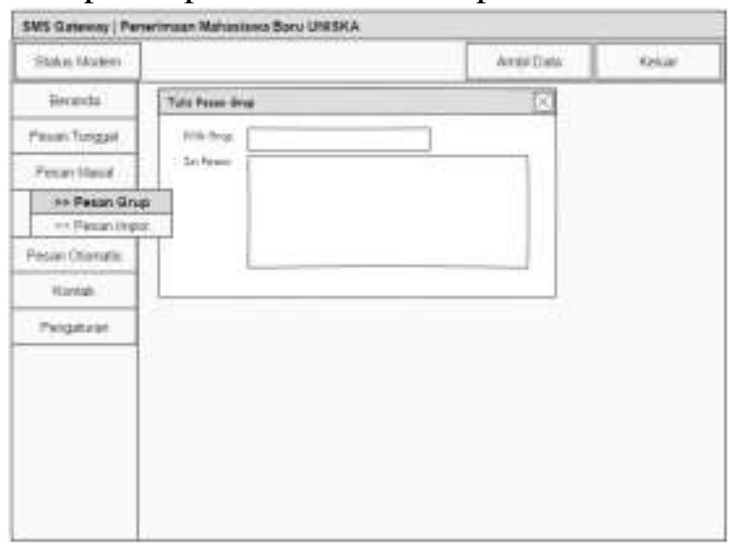

Gambar 7. Rancangan Laman Pesan Grup

Laman pesan grup digunakan untuk mengirim pesan secara sekaligus ke semua kontak yang grupnya dipilih.

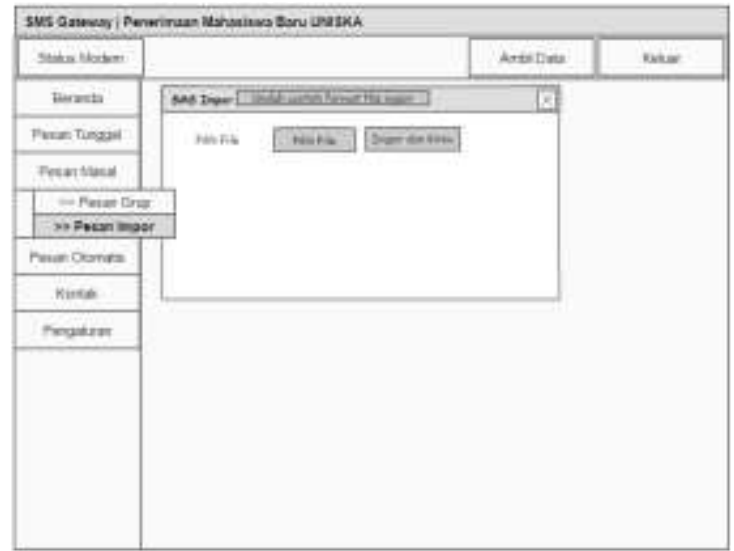

Gambar 8. Rancangan Laman Pesan Impor

Laman pesan impor digunakan untuk mengirim pesan yang nomor telepon dan isi pesannya dapat berbeda-beda, dengan aturan pengisian sesuai format yang telah disediakan.

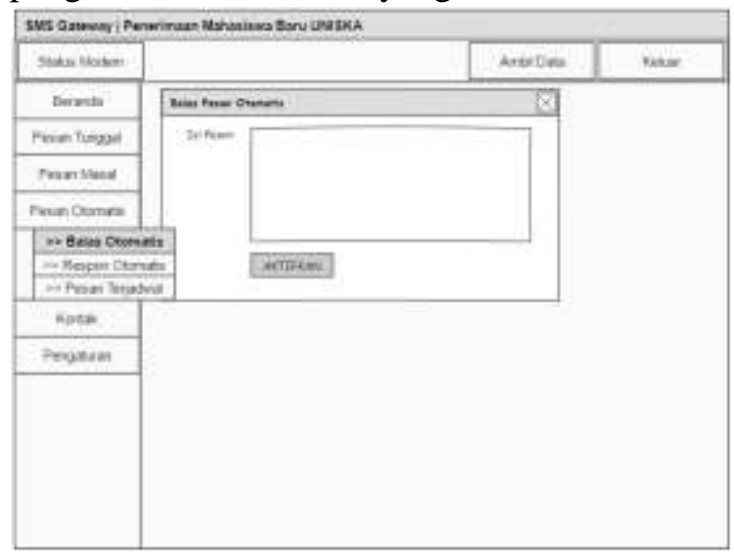

Gambar 9. Rancangan Laman Balas Otomatis

Laman balas otomatis digunakan untuk sistem secara otomatis dapat mengirim pesan jika ada pesan yang masuk ke dalam sistem.

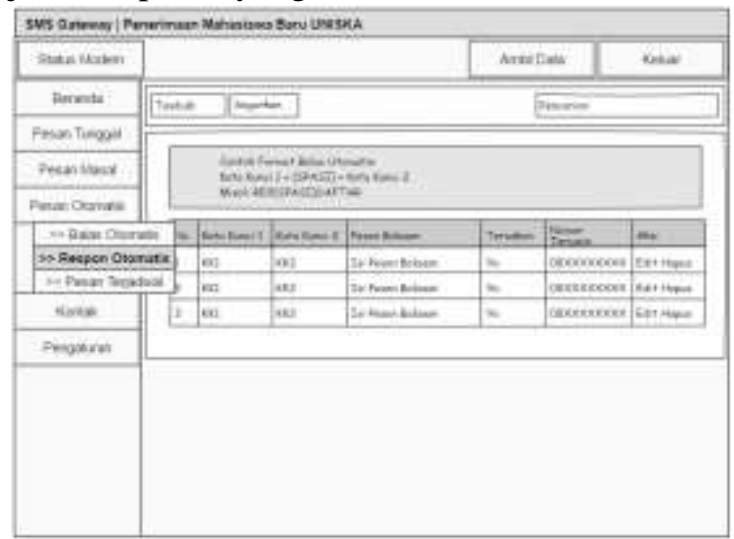

Gambar 10. Rancangan Laman Respon Otomatis

Laman respon otomatis adalah laman untuk mengelola kata kunci yang dapat membalas pesan masuk berdasarkan kata kunci yang telah ditentukan. 


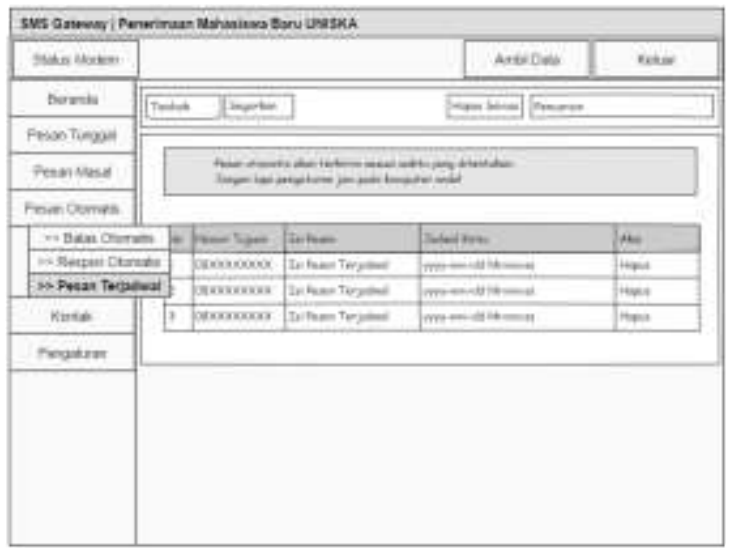

Gambar 11. Rancangan Laman Pesan

Terjadwal

Laman pesan terjadwal digunakan untuk membuat pesan yang dapat mengirim berdasarkan waktu tertentu.

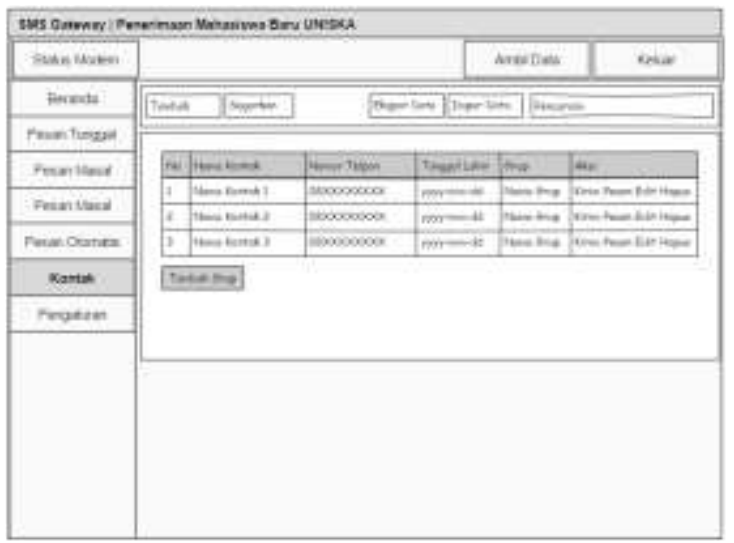

Gambar 12. Rancangan Laman Kontak

Laman kontak ini adalah laman untuk mengelola daftar kontak yang akan digunakan untuk dikirimi pesan.

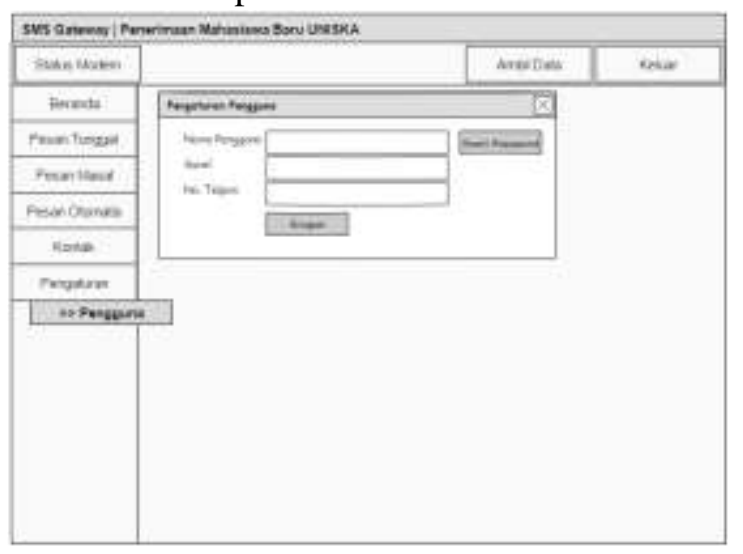

Gambar 13. Rancangan Laman Pengaturan

Pengguna

Laman pengaturan pengguna digunakan untuk memperbaharui data pengguna yang dapat mengakses sistem.

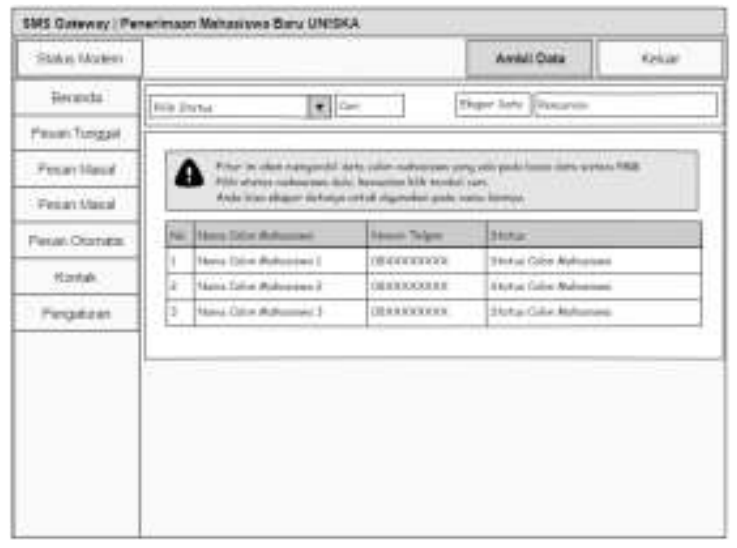

Gambar 14. Rancangan Laman Ambil Data

Laman ambil data berguna untuk mengambil dan mengumpulkan data calon mahasiswa yang ada pada basis data aplikasi mahasiswa baru

\section{HASIL DAN PEMBAHASAN}

1) Hasil dan Luaran yang Dicapai

Berdasarkan target dan luaran, dalam penelitian ini berhasil diintegrasikan sistem informasi penerimaan mahasiswa baru yang telah ada dengan menambahkan fitur SMS Gateway, basis data calon mahasiswa yang ada pada sistem terdahulu dapat digunakan untuk menambah daftar kontak secara langsung, dan akan digunakan untuk mengirim pesan secara masal. Fitur SMS dan respon otomatis juga dapat membantu pemberian informasi yang diperlukan oleh calon mahasiswa. Selain sistem yang dapat diimplementasikan luaran lain adalah draft publikasi dengan tujuan jurnal nasional dan draft buku ajar mengenai pengembangan sistem dengan metode waterfall. 
2) Antarmuka Sistem

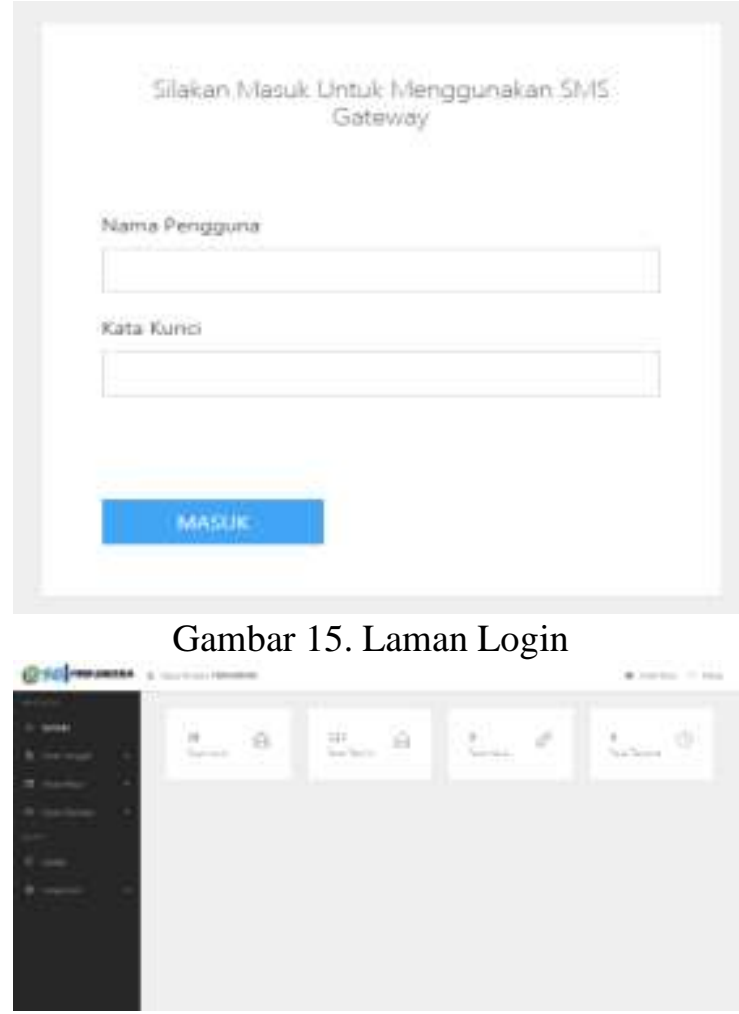

Gambar 16. Laman Beranda

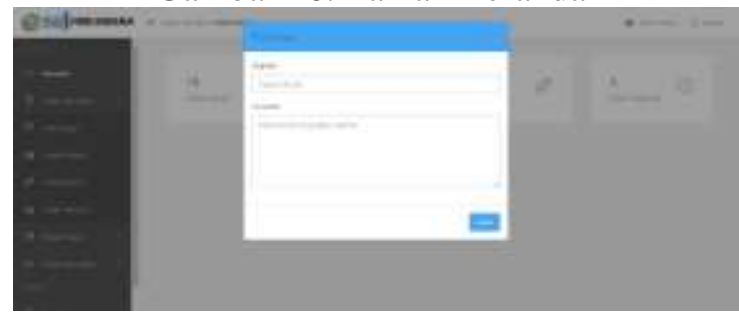

Gambar 17. Laman Tulis Pesan Tunggal

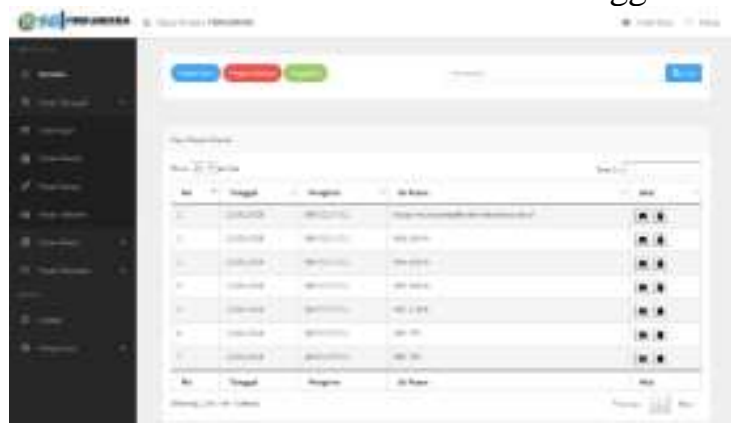

Gambar 18. Laman Pesan Masuk

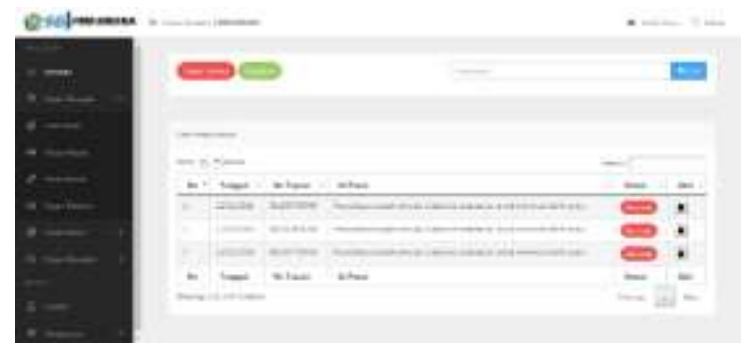

Gambar 19. Laman Pesan Keluar

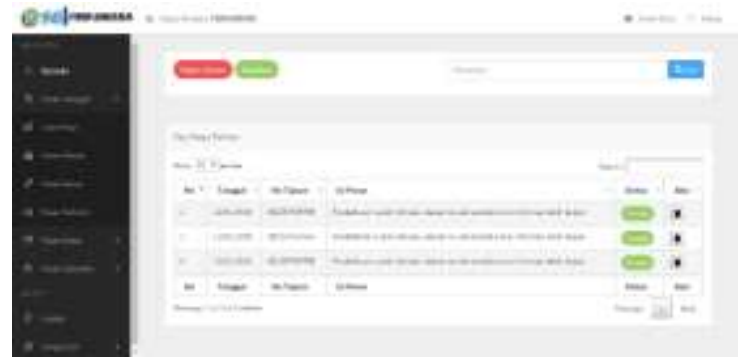

Gambar 20. Laman Pesan Terkirim

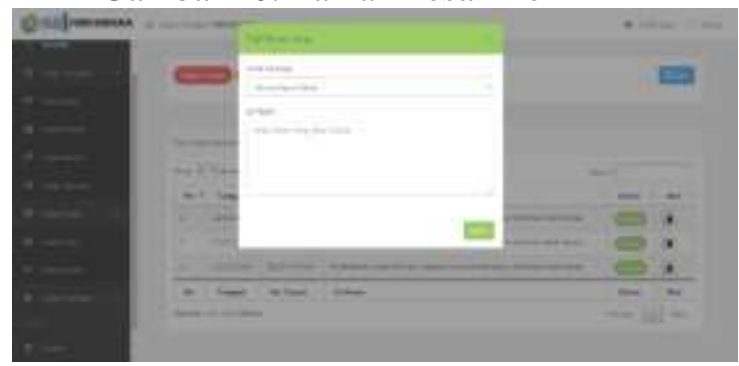

Gambar 21. Laman Pesan Grup

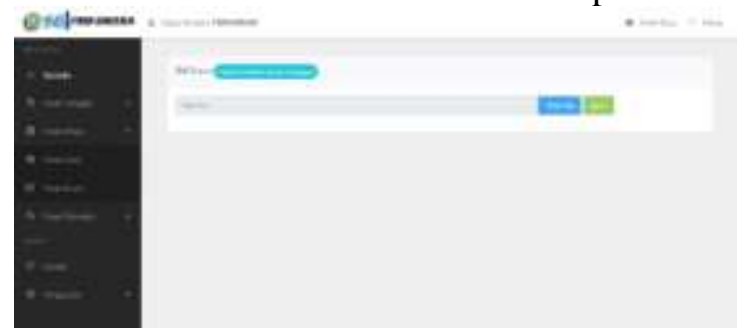

Gambar 22. Laman Pesan Impor

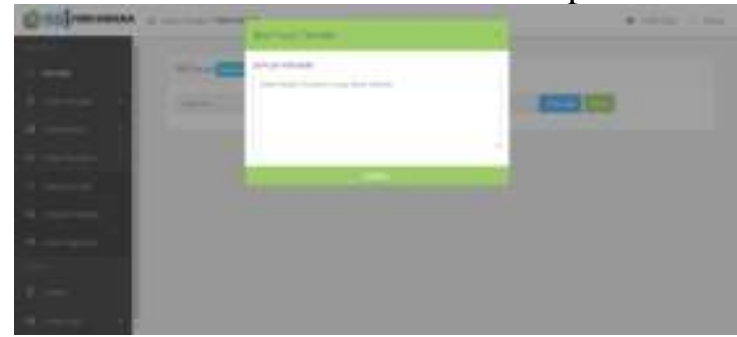

Gambar 23. Laman Balas Otomatis

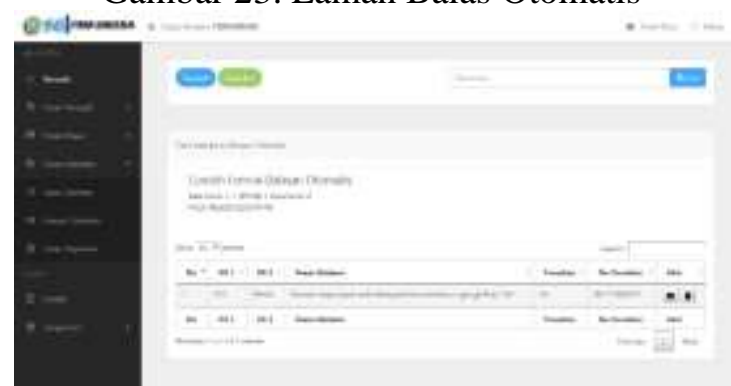

Gambar 24. Laman Respon Otomatis 


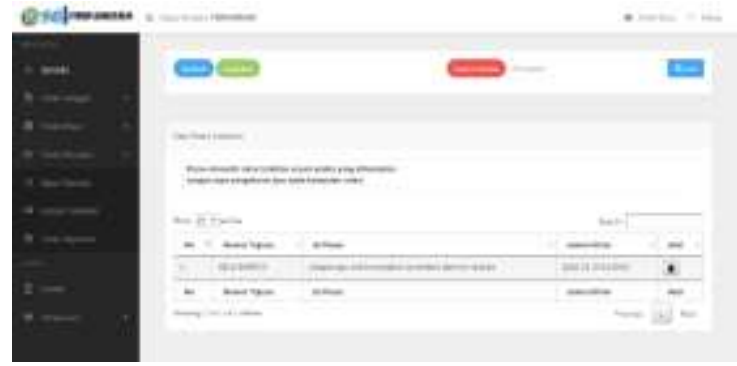

Gambar 25. Laman Pesan Terjadwal
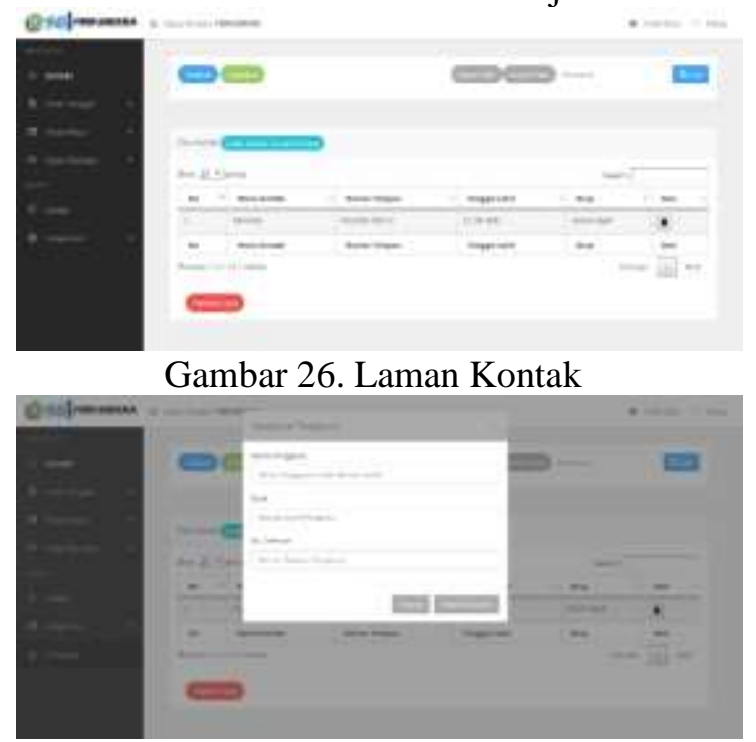

Gambar 27. Laman Pengaturan Pengguna

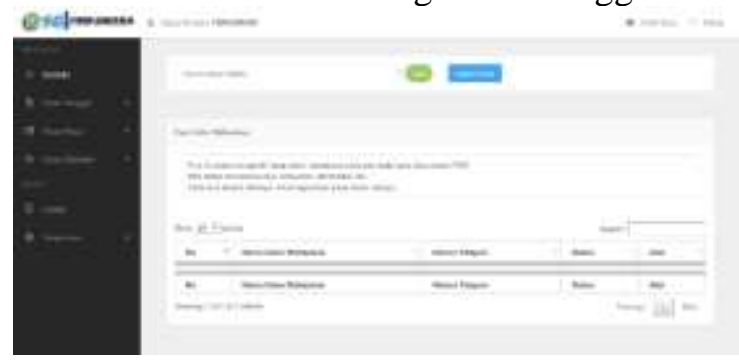

Gambar 28. Laman Ambil Data

3) Rencana Pengujian Pesan

Ada 2 (dua) pengujian yang akan dilakukan, yang pertama pengujian respon balasan SMS otomatis, bertujuan untuk mengetahui rata-rata lama balasan $S M S$ otomatis, waktu dihitung dari laporan SMS terkirim yang ada pada telepon pengguna sampai SMS kembali diterima pada telepon yang sama. Pengujian kedua adalah pengujian pengiriman pesan, bertujuan untuk mengetahui rata-rata lama pengiriman pesan, dalam pengujian ini akan dicoba pengiriman pesan ke banyak nomor yang berbeda, terdiri dari pengiriman ke 1, 5, 10 dan 50 nomor secara langsung, waktu dihitung dari SMS pertama diterima sampai $S M S$ terakhir diterima.
4) Hasil Pengujian Pesan

Pada pengujian respon $S M S$ otomatis, dari 10 kali percobaan didapatkan rata-rata waktu yang diperlukan untuk membalas 1 (satu) pesan adalah selama 14 detik dari laporan SMS terkirim sampai $S M S$ balasan diterima kembali, sedangkan untuk pengujian pengiriman SMS dari modem berikut hasil pengujian pengiriman pesan:

Tabel 1. Pengujian Pengiriman Pesan

\begin{tabular}{|c|l|c|c|c|}
\hline & \multicolumn{2}{|c|}{$\begin{array}{c}\text { Jenis } \\
\text { No. }\end{array}$} & $\begin{array}{c}\text { Banyak } \\
\text { Pencobaan } \\
\text { (kali) }\end{array}$ & \multicolumn{2}{|c|}{$\begin{array}{c}\text { Rata-Rata Lama } \\
\text { Pengiriman }\end{array}$} \\
\cline { 4 - 5 } & $\begin{array}{l}1 \text { nomor } \\
\text { tujuan }\end{array}$ & 10 & 26 & 0,43 \\
\hline 2 & $\begin{array}{l}5 \text { nomor } \\
\text { tujuan }\end{array}$ & 10 & 223 & 3,72 \\
\hline 3 & $\begin{array}{l}10 \text { nomor } \\
\text { tujuan }\end{array}$ & 10 & 320 & 5,33 \\
\hline 4 & $\begin{array}{l}50 \text { nomor } \\
\text { tujuan }\end{array}$ & 10 & 2287 & 38,12 \\
\hline
\end{tabular}

\section{PENUTUP}

1) Kesimpulan

Terdapat beberapa kesimpulan dari penelitian ini, antara lain:

1. Metode Waterfall dapat digunakan untuk menganalisa pengembangan Sistem Penerimaan Mahasiswa Baru dengan Penambahan Fitur SMS Gateway ini, rancangan sistem yang dibuat menjadi lebih mudah diintegrasikan dengan sistem yang telah berjalan;

2. Semua rancangan fitur SMS Gateway yang terdiri dari mengirim pesan tunggal, mengirim pesan grup, membalas pesan otomatis, respon pesan otomatis berdasarkan kata kunci tertentu berhasil diimplementasikan dan dapat digunakan berdampingan dengan sistem yang telah ada;

3. Penggunaan basis data dari sistem sebelumnya, mempermudah dan mempercepat proses penarikan (grabbing) data, khususnya data kontak calon mahasiswa yang kemudian dapat digunakan untuk pengiriman melalui SMS Gateway; 
2) Saran

Salah satu keberhasilan sistem agar terus hidup adalah dengan melakukan perbaikan secara berkelanjutan, untuk itu beberapa saran yang didapat dari penelitian ini, antara lain:

1. Penggunaan fitur SMS Gateway harus terus dikembangkan mengikuti perubahan-perubahan yang terjadi pada sistem yang terdahulu;

2. Fitur SMS Gateway hasil penelitian ini dapat terus dilanjutkan dengan penambahan kemampuan mengelola beberapa modem sekaligus agar dapat mempercepat pengiriman pesan;

3. Perlu dilakukan pengujian dengan modem dan provider telekomunikasi yang jenisnya berbeda dengan tujuan mengetahui perangkat terbaik;

4. Perlu dilakukan penelitian lanjutan yang mengangkat topik pengaruh komunikasi yang terjadi setelah adanya fitur $S M S$ Gateway dalam meningkatkan jumlah calon mahasiswa baru.

\section{DAFTAR PUSTAKA}

Alter, S. (1992). Information System: A Management Perspective. The Benjamin/Cummings Publishing.

Hall, J. A. (2001). Accounting Information Systems (3rd ed.). South Western College Publishing.

Harbiyanto, D. E. (2015). Sistem Informasi Pembayaran Sekolah Berbasis SMS Gateway Di SMK Bhinneka Karya 1 Boyolali.

Karch, M. (2010). Android for Work: Productivity for Professionals. New York: Appress.

Prasetyo, M. H., Asnawati, \& Arliando, Y. (2015). Sistem Informasi Nilai Mahasiswa Berbasis SMS Gateway Pada Fakultas Pertanian Universitas Bengkulu. Jurnal Media Infotama, 1120.

Rahayu, A. (2010). Pengembangan Sistem Penerimaan Siswa Baru Dengan SMS Gateway.

Saxena, N. \&. (2011). A secure digital signature approach for SMS security. International Journal of Computer Application (IJCA).
Turban, E. M. (1999). Information Technology for Management Making Connections for Strategis Advantage (2nd ed.). John Wiley \& Sons, Inc.

Wilkinson, J. W. (1992). Accounting and Information Systems. . John Wiley \& Sons, Inc. 